\title{
BMJ Open A multilevel analysis of mortality following acute myocardial infarction in Norway: do municipal health services make a difference?
}

\author{
Eliva Atieno Ambugo, Terje P Hagen
}

To cite: Ambugo EA, Hagen TP. A multilevel analysis of mortality following acute myocardial infarction in Norway: do municipal health services make a difference?. BMJ Open 2015;5:e008764. doi:10.1136/bmjopen-2015008764

- Prepublication history for this paper is available online. To view these files please visit the journal online (http://dx.doi.org/10.1136/ bmjopen-2015-008764).

Received 13 May 2015 Revised 30 September 2015 Accepted 16 October 2015

CrossMark

Department of Health Management and Health Economics, Institute of Health and Society, University of Oslo, Oslo, Norway

Correspondence to Eliva Atieno Ambugo; e.a.ambugo@medisin.uio.no

\section{ABSTRACT}

Objectives: Studies link area features such as neighbourhood socioeconomic deprivation to poor health outcomes. However, there is a paucity of research based on representative data investigating the effects of area-level health services on mortality. This study examines the extent to which municipal health services account for municipal variation in all-cause and cardiovascular disease (CVD) mortality. We hypothesise that unfavourable municipal features (eg, fewer available places for rehabilitation) are associated with higher risk of mortality after accounting for patients' characteristics.

Design: Population data from Norwegian national/ municipal registrars are analysed using multilevel logistic regression in this prospective cohort study. Setting and participants: The analytic sample (9412 patients aged 18+ from 336 municipalities) constitutes $87.7 \%$ of the nationwide population of Norwegian adults who were hospitalised for acute myocardial infarction (AMI) in 2009 and discharged alive.

Primary outcome measures: All-cause and CVD mortality occurring within 365 days after the first day of hospitalisation for AMI.

Results: There was a small but significant variation at the municipal level in all-cause mortality $(0.5 \%$; intraclass correlation coefficient $=0.005$ ) but not CVD mortality. There were no significant fixed effects of municipal health services on mortality in bivariate models. Patients' characteristics (eg, gender, comorbidities) fully accounted for the observed municipal variation in mortality. Being male versus female ( $O R=1.21,95 \% \mathrm{Cl} 1.02$ to 1.43 ), or having been previously diagnosed with dementia versus not (OR=2.06, $95 \% \mathrm{Cl} 1.53$ to 2.77 ) were also linked to higher odds of death.

Conclusions: Municipal variation in all-cause mortality for Norwegian patients with AMI appears to be driven not by differences across municipalities in health service levels, but by differences across municipalities in the composition of patients. Focusing on chronic disease prevention and treatment, and tackling personal and structural risk factors embedded within patients' sociodemographic characteristics, may be especially beneficial for longevity.

\section{Strengths and limitations of this study}

- The multilevel framework and the inclusion of a more comprehensive set of patients' characteristics made it possible to distinguish between compositional and contextual effects.

- The availability of population-wide registry data yields findings that directly pertain to patients with acute myocardial infarction from Norway in 2009.

- Selection effects may be at play in the analytic sample, for example, sick people for whom risk of death is more pronounced may select out of marriage or concern themselves more so than healthy people with their proximity to a healthcare facility-factors that may partially influence our findings.

\section{INTRODUCTION}

Cardiovascular diseases (CVD) are a leading cause of death globally. ${ }^{1}$ Risk factors for CVD and other causes of death have been identified at the person-level (tobacco use, sedentary lifestyle) and the area-level (income inequality). ${ }^{12}$ However, the effects on mortality of area-level measures of healthcare access and delivery are understudied. In Norway, as might be expected elsewhere, differences across municipalities in factors such as access to general practitioners (GPs) and nursing homes possibly influence longevity. The current study employs multilevel logistic regression to assess municipal variation in allcause and CVD mortality, and to examine the impact of municipal health services (MHS) on these outcomes for the Norwegian population of adults from 50 municipalities who were hospitalised with an acute myocardial infarction (AMI) / heart attack in 2009.

\section{BACKGROUND}

Contextual influences on mortality

In addition to person-level factors such as socioeconomic status (SES) and health 
behaviours, ${ }^{3}$ the contexts within which people's lives unfold, such as neighbourhoods or municipalities of residence, are also important influences on health. Areas of residence matter because their physical, social and structural features shape exposure to stressors and access to resources consequential to health. ${ }^{45}$ Research has linked adverse area traits to all-cause and CVD mortality. ${ }^{2}$ Some implicated factors include low SES and income inequality; ${ }^{6-11}$ urbanicity/population density; ${ }^{7911}$ and area-level indicators of family structure and social cohesion. ${ }^{12}{ }^{13}$ However, other studies have found no significant area effects on mortality. ${ }^{11}{ }^{14-16}$ These discrepant findings may be due to differences across the studies in the populations investigated (eg, Norway, Italy, the USA), duration of follow-up, person-level confounders controlled for and in the geographical units' demarcating area (eg, economic regions, census area units). Even so, two meta-analyses found modest and significant effects of income inequality and SES on mortality, suggesting that context may indeed matter. ${ }^{217}$

\section{Municipalities in Norway}

In Norway, responsibility for primary healthcare services, including those that are relevant for patients with AMI (eg, rehabilitation), lies with the country's 428 municipalities which operate as multipurpose governments with local taxes and block grants from the central government, the latter being their most important source of funding. ${ }^{18}{ }^{19}$ Revenues are allocated by municipal councils to various services (eg, health, education). A fundamental goal underlying the system for financing municipalities is to ensure that variation across municipalities in the amount/level and type of services provided stem from local needs, and reflect the priorities of each municipality and its constituents, as opposed to differences driven by unequal financial resources between the municipalities. Consequently, the grant system between the central government and the municipalities compensates municipalities with low tax revenues and high expected costs associated with delivering services. This decentralised model is, however, not matched by local autonomy regarding the types of services offered, for example. The municipalities remain heavily regulated by the central government and are better described as agents than partners.

Despite the central regulations, huge differences in service level among the municipalities exist. In general, small municipalities in rural areas have a higher service level than municipalities in urban areas. This reflects another goal of the Scandinavian welfare state-using municipalities as a measure for keeping unemployment low in remote areas. However, dealing with unemployment in this manner conflicts with the goal of low inequality. In view of such inherent disparities in the financing of municipal services, and considering that municipalities are a central unit for organising and delivering healthcare, we expect that municipal variation in service levels matter for all-cause and CVD mortality.

\section{The current study}

This study uses register data for Norwegian patients hospitalised with an AMI diagnosis in 2009 to: (1) assess municipal variation in all-cause and CVD mortality; and (2) given the significant municipal variation in these outcomes, to examine the effects of MHS on mortality. We hypothesise that unfavourable municipal features (eg, fewer GPs or fewer available places for rehabilitation) are associated with higher risk of mortality after accounting for patients' characteristics. Identifying MHS linked to mortality is relevant for public health because it sets the foundation for further inquiry into the potential mechanism through which the organisation and delivery of healthcare in Norway shapes survival and, in so doing, contributes to the evidence base for possible interventions.

\section{METHODS}

\section{Data and sample}

This study is designed after The European Health Care Outcomes, Performance and Efficiency (EuroHOPE) project. ${ }^{20} 21$ Data are from the following Norwegian national and municipal databases: hospital data (eg, diagnoses/treatment: Norwegian Patient Register), prescriptions (Norwegian Prescription Database), mortality dates (Norwegian Cause of Death Registry), sociodemographics (Statistics Norway's FD-trygd), MHS (Statistics Norway's KOSTRA-database). Health services data were linked to patients at the aggregate/municipal level. All other data were linked at the patient level. The study was approved by the Regional Committees for Medical and Health Research Ethics, South-East Norway and the Norwegian Data Inspectorate.

The analytic sample was derived from the population of 10729 people hospitalised for AMI (International Classification of Diseases 10 codes 121/122) in 2009 in Norway and discharged alive. An initial hospitalisation for AMI during this period constitutes an index admission. Individuals who were hospitalised with a main AMI diagnosis within 365 days before the index admission were excluded in order to homogenise the patient population. An additional 1317 patients were then sequentially excluded for these reasons: index admission's hospital stay exceeded 90 days $(\mathrm{n}=1)$, under age 18 $(n=2)$, lack of a Norwegian id $(n=4)$, the patient's municipality had missing data on MHS variables $(n=966)$, and missing data on patient variables $(n=344)$. The analytic sample thus includes 9412 patients distributed across 336 municipalities with between 1 and 989 patients (average 28).

In our data, there were 65 municipalities with five or fewer patients with AMI, 18 municipalities with two patients, and 7 municipalities with one patient. Given 
these sparse distributions-and possible concerns (in multilevel analyses) about biased estimates of variance components, fixed/random effects and $\mathrm{CIs}^{22}$-we performed sensitivity analyses on larger municipalities with at least 44 patients with AMI (analytic sample: 50 municipalities and 5532 patients).

\section{Measures}

The dependent variables are all-cause and CVD mortality (1=died, $0=$ otherwise) occurring within 365 days after the index admission day. CVD mortality captures CVD as the underlying cause of death based on ICD codes and as registered on the death certificate. ${ }^{23}$

Patients' sociodemographic and health characteristics included as control variables to reduce confounding of the association between MHS and mortality are: age at index admission (10-year units); gender (1=male, $0=$ female); education-primary, secondary, college/ university; marital status-married, not married, unknown; logarithm of average 2000-2008 individual income and wealth in thousands of kroner; logarithm of length of hospital stay in days (range: 1-221 days) for all conditions (except AMI) diagnosed within 365 days prior to the index admission; AMI severity $-\mathrm{ST}$ elevation myocardial infarction (STEMI)/recurrent, undefined AMI, non-STEMI; receipt of percutaneous coronary intervention $(P C I)$ within 2 days of the index admission (1=yes, $0=\mathrm{no})$; travel time in minutes (min) to the nearest PCI facility-under $30 \mathrm{~min}$ (under $35 \mathrm{~km}$, road ambulance), 30-59 min (35-69 km, ambulance), 60-119 min (70-536 km, helicopter), 120+ $\min (537+\mathrm{km}$, helicopter); and comorbidities diagnosed 365 days preindex admission $(1=$ condition present, $0=$ otherwise; 15 comorbidities total, eg, cancer, depression). Comorbidities were identified through hospital inpatient/outpatient visits 365 days prior to the index admission where the condition was the main/secondary diagnosis; or via prescriptions registered 365 days prior to the index admission.

The independent variables are eight municipal-level health services. As pertains to the services, which are described below, man-years measures the amount of work in hours completed by healthcare professionals in Norway in 2009. The services are: GP man-years for diagnoses/treatment; GP man-years for services to institutions other than tertiary centres and GP practices, for example, having a doctor on call at a nursing home or a rehabilitation centre; man-years for services provided by allied health professionals and that keep patients physically/socially active; man-years for long-term care services provided by all healthcare professionals; number of places (beds) in healthcare institutions (HCIs) for rehabilitation; number of places in HCIs for a short-term stay; total number of places across all HCIs adjusted for trading between municipalities; total number of open places on GPs' lists for new patients. To standardise these variables, each was divided by the number of inhabitants in the municipality, then multiplied by 1000 .

\section{Analysis plan}

Given our interest in contextual effects, we considered a hierarchical data structure where patients (level-1) were nested within municipalities (level-2). Our aim was to ascertain whether there was a significant municipal variation in risk of death and, if so, whether MHS accounted for such variation net of patients' characteristics. We used Stata V.13/SE and began the analyses by estimating a random intercept-only/null model that checked for municipal variation in all-cause and CVD mortality, this being a prerequisite for multilevel analysis concerned with contextual effects, such as this study.

In multilevel analysis, the intraclass correlation coefficient (ICC) assesses the proportion of variance in the outcome (eg, mortality) that is present at the group level (eg, municipality). The ICC for multilevel logistic regression is given by the formula: $\rho=\tau_{00} /\left(\tau_{00}+\pi^{2} / 3\right)$, where $\tau_{00}$ is the variance of the random intercept and $\pi^{2} / 3$ is the level-1 error variance. ${ }^{24}{ }^{25}$ The proportion of variation in mortality that is present at the individual/ patient level is given by $1-\rho$. The ICC for the null model in this study showed significant variation for allcause but not CVD mortality.

Next, we added patients' characteristics to the null model to see if they explained the significant municipal variation in all-cause mortality, and they did. Given that municipal variation in all-cause mortality was entirely compositional-due to the characteristics of patients in the municipalities, there was no justification for examining the contextual effects of MHS factors. We did estimate exploratory bivariate multilevel models with random intercepts and fixed effects of MHS to assess the presence of spurious contextual effects of MHS. In the final set of analyses, we estimated ordinary logistic regression models that examined the relationship between each of the patient-level characteristics (eg, gender, comorbidities) and all-cause/CVD mortality while controlling for the other characteristics of the patients in the model.

We performed the above analyses on our main sample of 9412 patients distributed across 336 municipalities, and repeated them as part of our sensitivity analyses on a sample of 5532 patients from larger municipalities (50 municipalities with at least 44 patients with AMI each). In the sensitivity analyses, we also checked for a significant municipal variation in all-cause and CVD mortality across five age groups (18-54 years old, 55-66, 67-74, $75-84$ and age $85+)$ and found none.

\section{RESULTS}

\section{Sample characteristics}

Table 1 shows the characteristics of the analytic sample $(\mathrm{N}=9412)$. There were more men than women. The sample comprised adults between the ages of 18 and 105 (mean 72) and the majority of them were married. A substantial proportion of the sample received only a primary education at best, and only one in eight patients 
Table 1 Characteristics of the Norwegian population of patients aged 18+ admitted to hospital with a primary diagnosis of AMI (2009, N=9412)

\begin{tabular}{|c|c|c|}
\hline Characteristic & Per cent/mean & SD \\
\hline Men (/women) & 61.3 & \\
\hline Age (years)* & 72.0 & 13.97 \\
\hline \multicolumn{3}{|l|}{ Age (categorical)* } \\
\hline $18-54$ years & 12.7 & \\
\hline $55-66$ & 23.0 & \\
\hline $67-74$ & 15.8 & \\
\hline 75-84 & 26.1 & \\
\hline $85+$ & 22.5 & \\
\hline \multicolumn{3}{|l|}{ Marital status } \\
\hline Married & 55.6 & \\
\hline Separated/divorced/widowed/never married & 30.3 & \\
\hline Status unknown & 14.1 & \\
\hline \multicolumn{3}{|l|}{ Education } \\
\hline Primary & 42.6 & \\
\hline Secondary & 45.0 & \\
\hline College/university (tertiary) & 12.5 & \\
\hline Individual income (thousands of kroner)* & 263.0 & 187.92 \\
\hline Individual wealth (thousands of kroner) ${ }^{\star}$ & 549.9 & 1210.40 \\
\hline Length of stay (within 365 days preindex admission)* & 5.8 & 13.72 \\
\hline \multicolumn{3}{|l|}{ AMI severity } \\
\hline STEMI/recurrent & 49.5 & \\
\hline Undefined AMI & 23.0 & \\
\hline Non STEMI & 27.4 & \\
\hline \multicolumn{3}{|l|}{ Minutes to nearest $\mathrm{PCl}$ facility } \\
\hline 0-29 (road ambulance) & 33.1 & \\
\hline 30-59 (road ambulance) & 18.3 & \\
\hline 60-119 (helicopter) & 24.6 & \\
\hline $120+$ (helicopter) & 24.0 & \\
\hline Received PCl (/no PCl) & 31.1 & \\
\hline \multicolumn{3}{|l|}{ Comorbidities (/no comorbidities) } \\
\hline Hypertension & 63.5 & \\
\hline Coronary artery disease & 14.1 & \\
\hline Diabetes mellitus & 15.6 & \\
\hline COPD† & 16.8 & \\
\hline Depression & 12.7 & \\
\hline Atrial fibrillation & 6.7 & \\
\hline Cardiac insufficiency/heart failure & 6.0 & \\
\hline Atherosclerosis & 1.9 & \\
\hline Cancer & 2.4 & \\
\hline Dementia & 4.0 & \\
\hline Parkinson's disease & 1.1 & \\
\hline Mental disorders & 3.3 & \\
\hline Renal insufficiency/failure & 3.1 & \\
\hline Alcoholism & 0.7 & \\
\hline Stroke & 3.6 & \\
\hline \multicolumn{3}{|l|}{ Comorbidities (count) ${ }^{*}$} \\
\hline Zero & 24.0 & \\
\hline One & 34.3 & \\
\hline Two & 20.4 & \\
\hline Three & 11.1 & \\
\hline At least four & 10.1 & \\
\hline All-cause mortality (/alive) & 18.6 & \\
\hline Cardiovascular disease mortality (/alive) & 10.3 & \\
\hline
\end{tabular}


was college educated. This, coupled with the wide range in income (kroner: median=221 383; range 0-8 172 944) and wealth (median=357 239; range 0-61 813 390), signals SES disparities. The average length of hospital stay (preindex admission) was under 1 week, with considerable variation (range 1-221 days). Most patients had STEMI, the most severe form of AMI. At index admission, around one-third of the patients lived within 30 min of a PCI facility, but there were many who lived over an hour away and were most likely transported by helicopter. Almost a third of the sample received PCI treatment. Of the 15 comorbidities assessed, hypertension was the most common (64\% of the sample) and alcoholism the least common (under 1\%). Almost a fifth of the total sample died from one of a variety of causes (ie, all-cause mortality $=18.6 \%$ ). Ten per cent of the total sample died from CVD. Of all the patients who died (ie, $18.6 \%$ of the total sample), the majority died from CVD $(55 \%)$.

In 2009, there were between 218 and 586860 (mean 13311 ) inhabitants across the 336 Norwegian municipalities examined here, and between 1 and 989 patients across these same municipalities. The supply of health services per 1000 inhabitants varied across the municipalities as shown in table 2. For example, GP man-years for diagnoses/treatment ranged from zero (eg, Utsira municipality) to 2.58 (Kvænangen), and the number of available places in HCIs for rehabilitation ranged from zero (eg, Utsira municipality) to 11.63 (Modalen). The extent to which such variation accounts for municipal differences in risk of mortality is the focus of this study.

\section{Municipal variation in mortality}

There was significant municipal variation in all-cause but not CVD mortality. Specifically in the null model, the variance of the random intercept was significant (estimate: $0.016 ; 95 \%$ CI 0.003 to 0.082 ). Additionally, the likelihood ratio of $\chi^{2}$ test (LR $\chi^{2}$ ) comparing the ordinary logistic to the multilevel logistic model was significant ( $\mathrm{LR} \chi^{2}=4.39, \mathrm{p}=0.018$ ), also indicating that the multilevel model was preferred. The ICC indicated that $0.5 \%(\rho=0.005)$ of the total variation in all-cause mortality was present at the municipal level. The remaining variation $(99.5 \%)$ was at the patient level. Sensitivity analyses based on an analytic sample of 5532 patients from across 50 municipalities generated similar results. The ICC indicated that $0.5 \%$ of the total variation in allcause mortality was present at the municipal level.

\section{Compositional/contextual influences on mortality}

Next, we added to the null model patients' sociodemographic and health characteristics (see table 1) to see if they accounted for the significant municipal variation in all-cause mortality (ie, $0.5 \%$ of the variance), and they did. The LR $\chi^{2}$ test comparing the ordinary logistic to the multilevel logistic model with patients' characteristics showed that the ordinary logistic model was preferred ( $\operatorname{LR} \chi^{2}=0.00, \mathrm{p}=1.00$ ). In the null model, $0.5 \%$ of variation in all-cause mortality was at the municipal level (ICC=0.005), but after adjusting for patients' characteristics, all the variation in mortality was explained away $(\mathrm{ICC}=0.000)$. Sensitivity analyses based on 5532 patients from across 50 municipalities yielded similar results.

Given that municipal variation in all-cause mortality was entirely compositional, there was no rationale for investigating the contextual effects of MHS factors on mortality. Even so, we estimated bivariate random intercept models with fixed effects of MHS to assess the presence of spurious contextual effects. We proceeded by adding, one at a time, each of the eight MHS to the null model to examine their effects on all-cause mortality. As shown in table 3 , a random intercept model with a fixed effect of MHS, and not ordinary logistic regression, was preferred for all eight MHS. The MHS did not explain any of the $0.5 \%$ variation in mortality at the municipal level (eg, models $2 \mathrm{a}$ and $2 \mathrm{~b}$ ), and some MHS even increased this variation (eg, models $2 \mathrm{c}$ and $2 \mathrm{~d}$ ), suggesting a suppression effect. Only one of the eight MHS had a significant fixed effect on mortality. Living in a municipality with more GP man-years for diagnoses was linked to a higher likelihood of death. However, this

\begin{tabular}{|c|c|c|c|c|}
\hline & Mean & SD & Minimum & Maximum \\
\hline GP man-years for diagnoses/treatment & 0.91 & 0.32 & 0.00 & 2.58 \\
\hline $\begin{array}{l}\text { GP man-years for services to all healthcare institutions (eg, nursing homes) except } \\
\text { for hospitals }\end{array}$ & 0.09 & 0.05 & 0.00 & 0.29 \\
\hline $\begin{array}{l}\text { Allied health professional man-years for services that keep patients physically/ } \\
\text { socially active }\end{array}$ & 0.64 & 1.01 & 0.00 & 10.64 \\
\hline All healthcare professional man-years for long-term care & 31.93 & 11.11 & 13.23 & 101.60 \\
\hline Number of places/beds in healthcare institutions for rehabilitation & 0.74 & 0.94 & 0.00 & 11.63 \\
\hline Number of places/beds in healthcare institutions for short-term stay & 1.57 & 1.45 & 0.00 & 17.44 \\
\hline $\begin{array}{l}\text { Total number of places/beds across healthcare institutions adjusted for trading } \\
\text { between municipalities }\end{array}$ & 10.82 & 5.29 & 2.06 & 36.36 \\
\hline Total number of places for new patients on GP lists & 124.69 & 208.55 & 0.00 & 2528.62 \\
\hline
\end{tabular}


Table 3 Bivariate multilevel logistic regression of all-cause mortality on municipal health services in Norway (level-1 N=9412 patients; level-2 $\mathrm{N}=336$ municipalities)

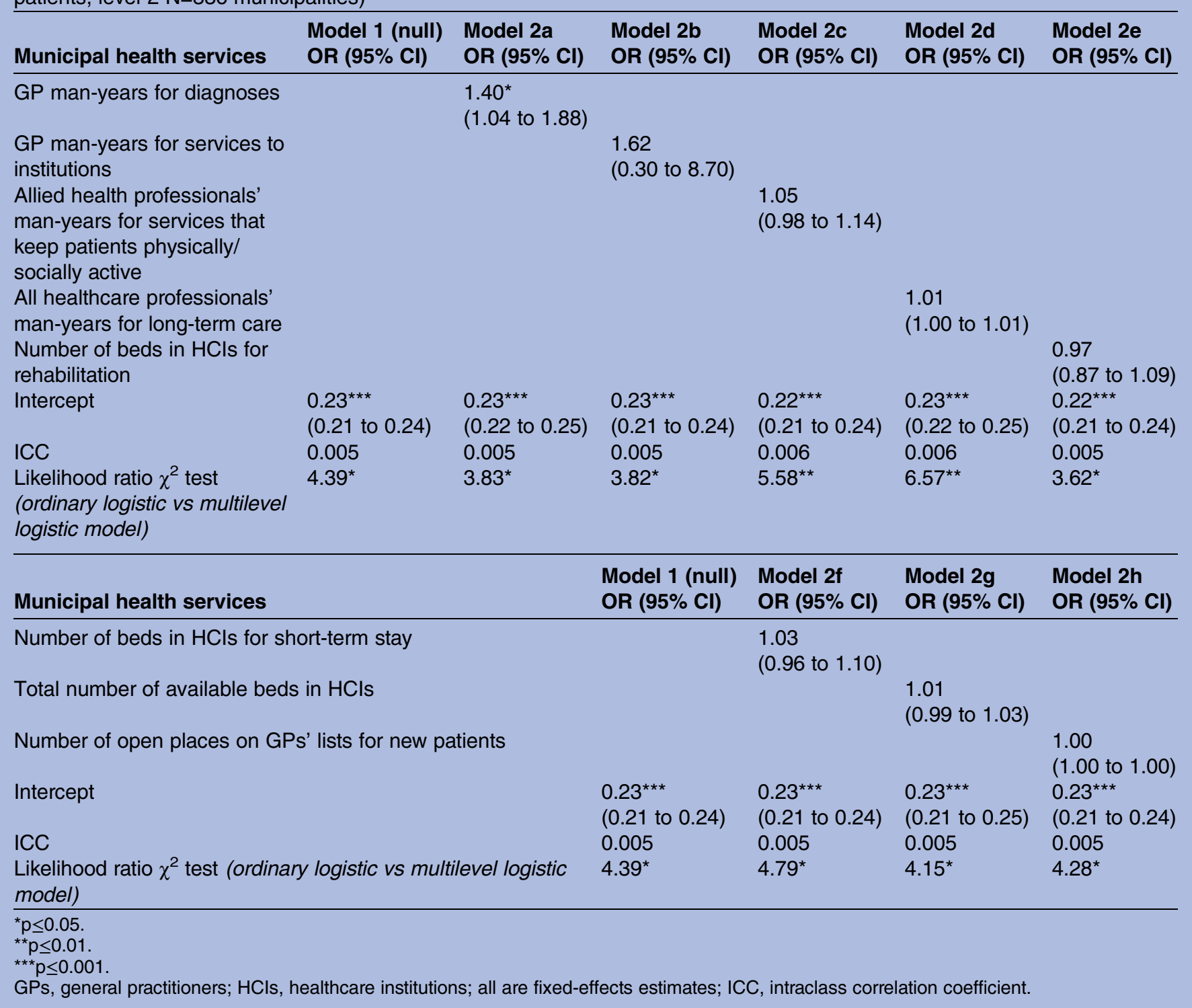

counterintuitive finding was not a true contextual effect given that, as previously noted, patients' characteristics explained away the little municipal variation in mortality $(0.5 \%)$ that was present.

Sensitivity analyses based on the larger municipalities generated somewhat similar results. As shown in tables 4 models $2 \mathrm{a}, 2 \mathrm{~b}$, and $2 \mathrm{f}-2 \mathrm{~h}$, the LR $\chi^{2}$ test indicated that multilevel bivariate models were preferred to ordinary logistic models, not for all eight MHS as was the case in the main results, but for five of them (GP man-years for diagnoses/treatment, GP man-years for services to institutions other than tertiary centres and GP practices, number of beds in HCIs for short-term stay, total number of available beds across all HCIs, and total number of open places on GPs' lists for new patients). As was the case in the main results overall, none of the aforementioned five MHS had a significant fixed effect on mortality. However, contrary to the main results where adding the MHS to the null model left unchanged or suppressed municipal variation in mortality, in the sensitivity analyses, the MHS generally reduced the variation by $20 \%$ (tables 4 models $2 \mathrm{a}, 2 \mathrm{~b}, 2 \mathrm{f}$ and $2 \mathrm{~h})$.

Although there are some differences in the results between our main analyses (based on 9412 patients, 336 municipalities) and the sensitivity analyses (based on 5532 patients, 50 municipalities), the key findings from both sets of analyses point to the same conclusions: (1) virtually all of the variation in all-cause mortality $(99.5 \%)$ is at the patient level; (2) what might appear to be significant contextual effects of MHS on mortality are spurious; (3) the little variation in all-cause mortality that is present at the municipal level $(0.5 \%)$ is due to the composition of patients in the municipalities. Findings from our main analyses are preferred to those from the sensitivity analyses because they pertain to a 
Table 4 Bivariate multilevel logistic regression of all-cause mortality on municipal health services in Norway (level-1 $\mathrm{N}=5532$ patients; level-2 $\mathrm{N}=50$ municipalities)

\begin{tabular}{|c|c|c|c|c|c|c|}
\hline Municipal health services & $\begin{array}{l}\text { Model } 1 \\
\text { (null) } \\
\text { OR (95\% Cl) }\end{array}$ & $\begin{array}{l}\text { Model 2a } \\
\text { OR }(95 \% \mathrm{Cl})\end{array}$ & $\begin{array}{l}\text { Model 2b } \\
\text { OR }(95 \% \mathrm{Cl})\end{array}$ & $\begin{array}{l}\text { Model 2c } \\
\text { OR }(95 \% \mathrm{Cl})\end{array}$ & $\begin{array}{l}\text { Model 2d } \\
\text { OR (95\% Cl) }\end{array}$ & $\begin{array}{l}\text { Model } 2 \mathrm{e} \\
\text { OR }(95 \% \mathrm{Cl})\end{array}$ \\
\hline GP man-years for diagnoses & & $\begin{array}{l}1.57 \\
\text { (0.59 to } 4.13)\end{array}$ & & & & \\
\hline $\begin{array}{l}\text { GP man-years for services } \\
\text { to institutions }\end{array}$ & & & $\begin{array}{l}3.40 \\
(0.16 \text { to } 71.35)\end{array}$ & & & \\
\hline $\begin{array}{l}\text { Allied health professionals' } \\
\text { man-years for services that } \\
\text { keep patients physically/ } \\
\text { socially active }\end{array}$ & & & & $\begin{array}{l}0.91 \\
(0.81 \text { to } 1.03)\end{array}$ & & \\
\hline $\begin{array}{l}\text { All healthcare professionals' } \\
\text { man-years for long-term care }\end{array}$ & & & & & $\begin{array}{l}1.00 \\
(0.98 \text { to } 1.02)\end{array}$ & \\
\hline $\begin{array}{l}\text { Number of beds in } \mathrm{HCls} \text { for } \\
\text { rehabilitation }\end{array}$ & & & & & & $\begin{array}{l}0.83 \\
\text { (0.64 to } 1.09)\end{array}$ \\
\hline Intercept & $\begin{array}{l}0.22^{* * *} \\
(0.20 \text { to } 0.24)\end{array}$ & $\begin{array}{l}0.22^{* * *} \\
(0.20 \text { to } 0.24)\end{array}$ & $\begin{array}{l}0.22^{\star * \star} \\
(0.20 \text { to } 0.24)\end{array}$ & $\begin{array}{l}0.22^{* * *} \\
(0.20 \text { to } 0.24)\end{array}$ & $\begin{array}{l}0.22^{\star * \star} \\
(0.20 \text { to } 0.24)\end{array}$ & $\begin{array}{l}0.22^{\star * \star} \\
(0.20 \text { to } 0.24)\end{array}$ \\
\hline $\begin{array}{l}\text { Intraclass correlation } \\
\text { coefficient }\end{array}$ & 0.005 & 0.004 & 0.004 & 0.003 & 0.005 & 0.003 \\
\hline $\begin{array}{l}\text { Likelihood ratio } \chi^{2} \text { test } \\
\text { (ordinary logistic vs } \\
\text { multilevel logistic model) }\end{array}$ & $4.37^{*}$ & $2.96^{\star}$ & $3.34^{*}$ & 2.15 & 2.14 & 1.86 \\
\hline \multicolumn{3}{|l|}{ Municipal health services } & $\begin{array}{l}\text { Model } 1 \text { (null) } \\
\text { OR }(95 \% \mathrm{Cl}) \\
\end{array}$ & $\begin{array}{l}\text { Model } 2 f \\
\text { OR }(95 \% \mathrm{Cl})\end{array}$ & $\begin{array}{l}\text { Model } 2 \mathrm{~g} \\
\text { OR }(95 \% \mathrm{Cl})\end{array}$ & $\begin{array}{l}\text { Model } 2 \mathrm{~h} \\
\text { OR }(95 \% \mathrm{Cl}) \\
\end{array}$ \\
\hline \multicolumn{4}{|c|}{ Number of beds in $\mathrm{HCls}$ for short-term stay } & $\begin{array}{l}0.90 \\
(0.76 \text { to } 1.06)\end{array}$ & & \\
\hline \multicolumn{4}{|c|}{ Total number of available beds in $\mathrm{HCls}$} & & $\begin{array}{l}1.05 \\
(0.99 \text { to } 1.11)\end{array}$ & \\
\hline \multicolumn{4}{|c|}{ Number of open places on GPs' lists for new patients } & & & $\begin{array}{l}1.00 \\
(1.00 \text { to } 1.00)\end{array}$ \\
\hline \multicolumn{3}{|l|}{ Intercept } & $\begin{array}{l}0.22^{\star \star \star} \\
(0.20 \text { to } 0.24)\end{array}$ & $\begin{array}{l}0.22^{\star \star \star} \\
(0.20 \text { to } 0.24)\end{array}$ & $\begin{array}{l}0.22^{\star \star \star} \\
(0.20 \text { to } 0.24)\end{array}$ & $\begin{array}{l}0.22^{\star \star \star} \\
(0.20 \text { to } 0.24)\end{array}$ \\
\hline \multicolumn{3}{|l|}{ Intraclass correlation coefficient } & 0.005 & 0.004 & 0.004 & 0.005 \\
\hline \multicolumn{3}{|c|}{$\begin{array}{l}\text { Likelihood ratio } \chi^{2} \text { test (ordinary logistic vs multilevel logistic } \\
\text { model) }\end{array}$} & $4.37^{\star}$ & $3.49^{*}$ & $3.00^{*}$ & $3.47^{\star}$ \\
\hline
\end{tabular}

larger number of Norwegian patients with AMI and are more precise (eg, the ORs/estimated effects of MHS in the bivariate models in table 3 have narrower CIs than similar estimates in table 4). We now proceed with the main analyses to examine (via ordinary logistic regression) the sociodemographic and health correlates of mortality.

\section{Sociodemographic and health correlates of all-cause and CVD mortality}

In table 5, Model 1 (all-cause mortality) and Model 2 (CVD mortality), the estimated OR for each covariate was adjusted for the other variables in the model. As shown in Model 1, men had 17\% higher odds of dying from any cause compared to women, and being unmarried versus married was associated with $18 \%$ higher odds of death. Wealthier patients were less likely to die. Specifically, a 1890 kroner increase in wealth was associated with a $7 \%$ decrease in the risk of death (natural $\log$ of wealth: $\mathrm{OR}=0.93,95 \%$ CI 0.88 to 0.99). Patients who, within 1 year prior to the index admission for AMI, had been hospitalised for a longer duration faced a higher risk of death. Specifically, a 2.7-day increase in the length of hospital stay was associated with a 20\% increase in the odds of death (natural $\log$ of length of stay: $\mathrm{OR}=1.20,95 \%$ CI 1.13 to 1.28 ).

The odds of death for people who were previously diagnosed with a mental disorder or cancer was, respectively, 1.75 and 3.14 times that of people without these conditions. People who were previously diagnosed with coronary artery disease versus not had 29\% lower odds 
Table 5 Adjusted logistic models: sociodemographic and health correlates of all-cause and CVD mortality among Norwegian patients with AMI (2009: $\mathrm{N}=9412)$

\begin{tabular}{|c|c|c|c|c|}
\hline \multirow[b]{2}{*}{ Characteristic } & \multicolumn{2}{|c|}{$\begin{array}{l}\text { Model } 1 \\
\text { All-cause mortality }\end{array}$} & \multicolumn{2}{|c|}{$\begin{array}{l}\text { Model } 2 \\
\text { CVD mortality }\end{array}$} \\
\hline & $\overline{\text { OR }}$ & $95 \% \mathrm{Cl}$ & $\overline{\text { OR }}$ & $95 \% \mathrm{Cl}$ \\
\hline Men (/women) & $1.17^{\star}$ & (1.02 to 1.33$)$ & 1.15 & (0.98 to 1.34$)$ \\
\hline Age (10-year units) & $2.29^{\star \star \star}$ & (2.12 to 2.46 ) & $2.12^{\star \star *}$ & (1.93 to 2.32$)$ \\
\hline \multicolumn{5}{|l|}{ Marital status $\dagger$} \\
\hline Separated/divorced/widowed/never married & $1.18^{*}$ & (1.03 to 1.35$)$ & 1.13 & (0.96 to 1.33$)$ \\
\hline Status unknown & 0.83 & (0.66 to 1.03 ) & 0.76 & (0.58 to 1.03$)$ \\
\hline \multicolumn{5}{|l|}{ Educationt } \\
\hline Secondary & 0.94 & (0.82 to 1.07$)$ & 0.91 & (0.78 to 1.07$)$ \\
\hline College/university (tertiary) & 0.85 & (0.67 to 1.09 ) & 0.85 & (0.63 to 1.14$)$ \\
\hline Individual income (log) & 0.90 & (0.74 to 1.10$)$ & 0.87 & (0.68 to 1.11$)$ \\
\hline Individual wealth (log) & $0.93^{\star}$ & (0.88 to 0.99$)$ & 0.99 & (0.91 to 1.06$)$ \\
\hline \multicolumn{5}{|l|}{ AMI severity $\dagger$} \\
\hline Undefined AMI & $0.77^{\star \star \star}$ & (0.67 to 0.90$)$ & $0.60^{* \star *}$ & (0.51 to 0.72$)$ \\
\hline Non STEMI & $0.53^{\star \star \star}$ & (0.45 to 0.61$)$ & $0.41^{\star \star *}$ & (0.33 to 0.50$)$ \\
\hline \multicolumn{5}{|l|}{ Minutes to nearest $\mathrm{PCl}$ facility $\dagger$} \\
\hline 30-59 (road ambulance) & 0.95 & (0.79 to 1.13 ) & 1.15 & (0.93 to 1.43$)$ \\
\hline 60-119 (helicopter) & 0.92 & (0.78 to 1.09$)$ & 1.15 & (0.94 to 1.40$)$ \\
\hline $120+$ (helicopter) & 0.95 & (0.81 to 1.11$)$ & 1.09 & (0.90 to 1.32$)$ \\
\hline Received PCl (/no PCl) & $0.36^{\star \star \star}$ & (0.29 to 0.44$)$ & $0.41^{\star \star \star}$ & (0.31 to 0.53$)$ \\
\hline Length of stay (1st hospital episode, log) & $1.20^{\star \star \star}$ & (1.13 to 1.28$)$ & 1.02 & (0.94 to 1.10$)$ \\
\hline \multicolumn{5}{|l|}{ Comorbidities (/no comorbidities) } \\
\hline Hypertension & 0.96 & (0.83 to 1.11$)$ & 0.94 & (0.79 to 1.12$)$ \\
\hline Coronary artery disease & $0.71^{\star * *}$ & (0.59 to 0.85$)$ & 0.81 & (0.65 to 1.01$)$ \\
\hline Diabetes mellitus & $1.39^{\star \star *}$ & (1.19 to 1.62$)$ & $1.24^{*}$ & (1.02 to 1.49$)$ \\
\hline COPD $\ddagger$ & 1.05 & (0.90 to 1.23 ) & 0.97 & (0.80 to 1.17$)$ \\
\hline Depression & $1.21^{*}$ & (1.02 to 1.43 ) & $1.24^{*}$ & (1.02 to 1.51$)$ \\
\hline Atrial fibrillation & 1.07 & (0.86 to 1.32$)$ & 1.19 & (0.92 to 1.52$)$ \\
\hline Cardiac insufficiency/heart failure & $1.56^{\star \star \star}$ & (1.25 to 1.95$)$ & $1.42^{\star *}$ & (1.10 to 1.84$)$ \\
\hline Atherosclerosis & 1.08 & (0.74 to 1.58$)$ & 1.46 & (0.95 to 2.23$)$ \\
\hline Cancer & $3.14^{\star \star \star}$ & (2.28 to 4.33 ) & 1.19 & (0.77 to 1.82$)$ \\
\hline Dementia & $2.13^{\star \star \star}$ & (1.69 to 2.68 ) & $1.78^{\star \star \star}$ & (1.39 to 2.30$)$ \\
\hline Parkinson's disease & 1.24 & (0.78 to 1.96$)$ & 1.10 & (0.63 to 1.93 ) \\
\hline Mental disorders & $1.75^{\star \star \star}$ & (1.29 to 2.39 ) & 1.39 & (0.94 to 2.04$)$ \\
\hline Renal insufficiency/failure & $2.14^{\star \star \star}$ & (1.61 to 2.84 ) & $1.59^{\star \star}$ & (1.16 to 2.18$)$ \\
\hline Alcoholism & 1.43 & (0.74 to 2.77 ) & 1.74 & (0.78 to 3.92$)$ \\
\hline Stroke & 0.96 & (0.73 to 1.26$)$ & 1.12 & (0.82 to 1.54$)$ \\
\hline Intercept & $0.00^{\star \star \star}$ & (0.00 to 0.00$)$ & $0.00^{\star \star *}$ & (0.00 to 0.01$)$ \\
\hline
\end{tabular}

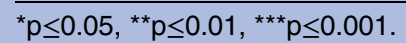

†Omitted reference groups: married persons; primary education; STEMI/recurrent STEMI; 0-29 min from PCI unit (road ambulance).

$¥$ Chronic obstructive pulmonary disease and asthma.

AMI, acute myocardial infarction; CVD, cardiovascular diseases; PCI, percutaneous coronary intervention; STEMI, ST elevation myocardial infarction.

of death, possibly reflecting a beneficial treatment effect or less aggressive disease progression. As shown in Model 2, none of the foregoing characteristics were linked to risk, or group differences in risk, of CVD mortality, possibly due to the small sample bias, ${ }^{26}{ }^{27}$ considering that a smaller proportion of the sample died from CVD (10\%). For all-cause and CVD mortality, having received PCI treatment versus not was protective, whereas older patients had a higher risk of death. As shown in table 5 Model 1 , patients who were diagnosed with chronic conditions including diabetes mellitus, depression, heart failure, dementia and renal insufficiency had a higher odds of death than patients without these conditions. Factors such as education, income, distance to the nearest PCI facility and conditions such as hypertension and alcoholism were not linked to risk, or group differences in risk, of death.

\section{DISCUSSION}

This study's aim was to examine, within a multilevel framework, the influence of MHS on all-cause and CVD mortality in the Norwegian population of patients with AMI (year 2009). We found a small but significant municipal variation in all-cause but not CVD mortality, and it 
was entirely compositional, that is, due to the characteristics of the patients. Turning to patients' traits, we found that being male, older, less wealthy or not married was associated with a higher likelihood of death -which is consistent with the extant literature on social determinants of health. ${ }^{328}$ It thus appears that SES (eg, wealth) disparities in mortality persist even in Norway, a relatively egalitarian country with generous and largely universal welfare supports. Also, as expected, patients who received PCI treatment were less likely to die, whereas persons with a longer length of hospital stay prior to the index admission, and those who were previously diagnosed with a chronic condition, faced a higher risk-with cancer, renal failure and dementia posing the greatest threats.

Study strengths include the population-wide registry data which have generated findings that are applicable to patients with AMI from across Norway. Additionally, the multilevel framework and the inclusion of a more comprehensive set of patients' characteristics made it possible to distinguish between compositional and contextual effects. ${ }^{24}{ }^{29}$ We cannot rule out the possibility of selection effects, which is a limitation of this study. Sick people, for whom risk of death is more pronounced, may select out of marriage ${ }^{30}$ or concern themselves more so than healthy people with matters related to healthcare access (eg, the proximity of one's residence to a hospital). Although we statistically controlled for many health conditions, our efforts are not comprehensive. Consequently, differences between sick and healthy individuals may explain some of the observed group differences in risk of death.

In summary, we found that a patient's municipality of residence does not play a prominent role in shaping his/her likelihood of death, leading to the conclusion that attention should be focused instead on the characteristics of patients that might undermine longevity. Even so, attention should also be directed at structural factors that are beyond a patient's realm of influence, ${ }^{5}$ and that possibly underlie the observed associations between the patient's characteristics (eg, wealth) and mortality.

Contributors TPH conceptualised and designed the study after the European Health Care Outcomes, Performance and Efficiency project; and contributed to the background. EAA analysed the data and drafted the manuscript. Both authors reviewed drafts of the article.

Funding This work was supported by the Norwegian Research Council grant numbers 220764 and 229092.

\section{Competing interests None declared.}

Ethics approval Granted by the Regional Ethics Committee South-East, Norway; and the Norwegian Data Inspectorate.

Provenance and peer review Not commissioned; externally peer reviewed.

Data sharing statement No additional data are available.

Open Access This is an Open Access article distributed in accordance with the Creative Commons Attribution Non Commercial (CC BY-NC 4.0) license, which permits others to distribute, remix, adapt, build upon this work noncommercially, and license their derivative works on different terms, provided the original work is properly cited and the use is non-commercial. See: http:// creativecommons.org/licenses/by-nc/4.0/

\section{REFERENCES}

1. World Health Organization. Cardiovascular diseases (CVD). 2015. http://www.who.int/mediacentre/factsheets/fs317/en/ (accessed 19 Jan 2015)

2. Meijer M. Neighbourhood context and mortality: an overview. In: Stock C, Ellaway A, eds. Neighbourhood structure and health promotion. New York: Springer, 2013:11-37.

3. World Health Organization, World Heart Federation and World Stroke Organization. Global atlas on cardiovascular disease prevention and control. Report. Geneva: World Health Organization, 2011.

4. Aneshensel CS. Neighborhood as a social context of the stress process. In: Avison WR, Aneshensel CS, Schieman S, et al., eds Advances in the conceptualization of the stress process: essays in honor of Leonard I. Pearlin, NY: Springer Science \& Business Media, 2010:35-52.

5. Bronfenbrenner U. Developmental research, public policy, and the ecology of childhood. Child Dev 1974;45:1-5.

6. Dahl E, Ivar Elstad J, Hofoss D, et al. For whom is income inequality most harmful? A multi-level analysis of income inequality and mortality in Norway. Soc Sci Med 2006;63:2562-74.

7. Meijer M, Mette KA, Stock C, et al. Population density, socioeconomic environment and all-cause mortality: a multilevel survival analysis of 2.7 million individuals in Denmark. Health Place 2012;18:391-9.

8. Martikainen P, Kauppinen TM, Valkonen T. Effects of the characteristics of neighbourhoods and the characteristics of people on cause specific mortality: a register based follow up study of 252 000 men. J Epi Comm Health 2003;57:210-17.

9. Curtis $\mathrm{S}$, Southall $\mathrm{H}$, Congdon $\mathrm{P}$, et al. Area effects on health variation over the life-course: analysis of the longitudinal study sample in England using new data on area of residence in childhood. Soc Sci Med 2004;58:57-74.

10. Backlund E, Rowe G, Lynch J, et al. Income inequality and mortality: a multilevel prospective study of 521248 individuals in 50 US states. Int J Epidemiol 2007;36:590-6.

11. Blakely $\mathrm{T}$, Atkinson $\mathrm{J}$, Ivory $\mathrm{V}$, et al. No association of neighbourhood volunteerism with mortality in New Zealand: a national multilevel cohort study. Int J Epidemiol 2006;35:981-9.

12. Kravdal $\varnothing$. Does income inequality really influence individual mortality? Results from a 'fixed-effects analysis' where constant unobserved municipality characteristics are controlled. Dem Res 2008;18:205-32.

13. Chaix B, Lindström M, Rosvall M, et al. Neighbourhood social interactions and risk of acute myocardial infarction. J Epi Comm Health 2008;62:62-8.

14. Henriksson G, Weitoft GR, Allebeck P. Associations between income inequality at municipality level and health depend on context-a multilevel analysis on myocardial infarction in Sweden. Soc Sci Med 2010;71:1141-9.

15. Petrelli A, Gnavi R, Marinacci C, et al. Socioeconomic inequalities in coronary heart disease in Italy: a multilevel population-based study. Soc Sci Med 2006;63:446-56.

16. Blakely T, Atkinson J, O'Dea D. No association of income inequality with adult mortality within New Zealand: a multi-level study of 1.4 million 25-64-year-olds. J Epi Comm Health 2003;57:279-84.

17. Kondo N, Sembajwe G, Kawachi I, et al. Income inequality, mortality, and self-rated health: meta-analysis of multilevel studies. BMJ 2009;339:b4471.

18. Rattsø J. Local government allocation of labour and the grant system: an applied model analysis of local government behaviour in Norway. Environ Plann D 1989;7:273-84.

19. Rattsø J, Sørensen RJ. Local governments integrated in a welfare state: a review of Norwegian local government performance. In: Ratts $\varnothing \mathrm{J}$, ed. Fiscal federalism and state-local finance: the Scandinavian perspective. Cheltenham, UK: Edward Elgar, 1998:49-68

20. Häkkinen U, Iversen T, Peltola M, et al. Health care performance comparison using a disease-based approach: the EuroHOPE project. Health Policy 2013;112:100-9.

21. Peltola $M$, Juntunen $M$, Häkkinen $U$, et al. A methodological approach for register-based evaluation of cost and outcomes in health care. Ann Med 2011;43(Suppl 1):S4-13.

22. Schoeneberger JA. The impact of sample size, prevalence, estimation method and other factors when estimating multilevel logistic models [PhD Thesis]. USA: University of South Carolina, 2012.

23. Statistics Central Bureau Norway. Cause of death 2012: About the statistics. 2012. http://www.ssb.no/en/helse/statistikker/dodsarsak/ aar/2013-11-01?fane=om\#content (accessed 13 Apr 2015). 
24. Raudenbush SW, Bryk AS, Cheong YF, et al. HLM 7: hierarchical linear and nonlinear modeling. Lincolnwood, IL: Scientific Software International Inc, 2011.

25. Clarke P. When can group level clustering be ignored? Multileve models versus single-level models with sparse data. J Epi Comm Health 2008;62:752-8.

26. Firth D. Bias reduction of maximum likelihood estimates. Biometrika 1993;80:27-38.

27. Allison P. Logistic regression for rare events. 2012. http://www. statisticalhorizons.com/logistic-regression-for-rare-events (accessed 13 Apr 2015).
28. Marmot M. Introduction. In: Marmot M, Wilkinson RG, eds. Social determinants of health. 2nd edn. Oxford, UK: Oxford University Press, 2005:12-17.

29. Austin PC, Tu JV, Alter DA. Comparing hierarchical modeling with traditional logistic regression analysis among patients hospitalized with acute myocardial infarction: should we be analyzing cardiovascular outcomes data differently?. Am Heart J 2003;145:27-35.

30. Blekesaune M, Øverbye E, Romøren TI. Health selection in marital transitions: Evidence from administrative data. In: Blekesaune $M$ and Øverbye E, eds. Familieendring, helse og trygd: Fire longitudinelle studier. Norwegian Social Research (NOVA) Report \#22/03 2003:34-52. 